\title{
5. CORING-INDUCED MAGNETIZATION OF RECOVERED SEDIMENT ${ }^{1}$
}

\author{
M. Fuller, ${ }^{2}$ M. Hastedt,${ }^{3}$ and B. Herr ${ }^{4}$
}

\begin{abstract}
Shipboard measurements of archived advanced piston corer (APC) cores during Leg 157 revealed a preponderance of radially inward-directed magnetization. The nature of the radial magnetization was investigated with tests on a wash core. The coring-induced magnetization has higher coercivity than a simple isothermal remanent magnetization (IRM). Well-lithified samples do not have this coring-induced, high-coercivity contamination. The coring-induced moment, therefore, appears to be related to the coring or recovery process in relatively poorly lithified sediments.

The magnetic fields of bottom-hole assemblies (BHAs), APC barrels, and APC cutting shoes were measured as possible source fields for the drill moments. Fields of tens of $\mathrm{mT}$ were found in the core barrels, with fields only 1 order of magnitude smaller at the cutting edge of the shoes. The fields associated with the BHAs were weaker and fell off rapidly on the scale length of the drill bit. The coring-induced magnetization appears to be caused by the mechanical disturbance of sediments during coring, pull-out, or passage up the drill string in the presence of the field of the APC barrel.
\end{abstract}

\section{INTRODUCTION}

The problem of coring-induced magnetization in sediments recovered by the Ocean Drilling Program (ODP) and its antecedent, the Deep Sea Drilling Project (DSDP), has a long history. As the Handbook for Shipboard Paleomagnetists notes: "Perhaps the most common complaint of paleomagnetists working with ODP cores is the presence of a remanence thought to have been acquired during drilling and/or recovery of the core ...."(Stokking et al., 1993). We use the term "coring-induced magnetization," following Roberts et al., (1996), because the effect is seen in the piston cores recovered with the advanced piston corer (APC). This usage distinguishes between magnetization arising from coring to that generated from using the rotary core barrel (RCB) cores.

The coring-induced magnetization did not invalidate shipboard magnetostratigraphy during Leg 157, because the latitude of the site gave a strong vertical component of magnetization from which polarity could usually be determined. However, the predominance of $+\mathrm{X}$ magnetization giving $0^{\circ}$ declination in archived half-cores obscured the magnetic record. In this paper, we discuss the following: (1) earlier reports of coring-induced magnetization; (2) the characterization of these magnetizations; (3) measurements of the magnetic fields of bottom-hole assemblies (BHAs), piston core barrels, and cutting shoes; and (4) the simulation and recognition of the effect of radial coring-induced magnetization.

\section{REVIEW OF PREVIOUS WORK}

An early description of coring-induced moments was given in the Initial Reports volume for DSDP Leg 90 (Barton and Bloemendal, 1986). Measurements were made using the Digico spinner magnetometer aboard ship, followed by the Sct cryogenic magnetometer at the University of Rhode Island. The sediments were weakly magnetized carbonates. The natural remanent magnetization (NRM) was categorized as follows:

${ }^{1}$ Weaver, P.P.E., Schmincke, H.-U., Firth, J.V., and Duffield, W. (Eds.), 1998. Proc. $O D P$, Sci. Results, 157: College Station, TX (Ocean Drilling Program).

${ }^{2}$ SOEST-Hawaii Institute of Geophysics and Planetology, University of Hawaii, Honolulu, HI 96822, U.S.A. mfuller@ soest.hawaii.edu

${ }^{3}$ Ocean Drilling Program, Texas A \& M University Research Park, 1000 Discovery Drive, College Station, TX 77845-9547, U.S.A.

${ }^{4}$ Institut für Allgemeine und Angewandte Geophysik, Universitat Munchen, Theresienstrasse, D-80333, München, Federal Republic of Germany.
1. Single stable remanence component with minor low coercivity, or soft overprint of the same sign;

2. Same as (1), but with overprint of opposite sign;

3. Two overprint components, one in present field direction and the other with steep inclination, which has high coercivity, or hard magnetization; and

4. Same, but with a softer steep component.

The hard, near-vertical magnetization seen in (3) and its counterpart in (4) were interpreted as coring-induced moments. Bleil (1989), who used the pass-through cryogenic magnetometer during Leg 107, reported that results were disappointing because of extensive overprints. Comparison of discrete sample measurements with the longcore measurements revealed that the coring-induced moment was strongest in the outer parts of the core (Bleil, 1989). Similar results were reported by Tauxe et al. (1989) and Hall and Sager (1990). The latter authors indicated that the presence of overprints with positive and negative inclinations implied that the coring-induced moments were probably caused by the remanence of the core barrels. As a result, they measured the axial fields within core barrels in their initial state, after demagnetization, and after a subsequent single round-trip to the ocean floor. They found that after the single round-trip, the barrels had acquired a comparable remanent magnetization to that present before demagnetization. This experiment was repeated during Leg 146 (R.J. Musgrave, pers. comm., 1996), with similar results.

Particularly important results correlating some of the coringinduced magnetization to the APC barrels had been reported by Schneider and Vandamme in the Initial Reports volume for Leg 115 (Shipboard Scientific Party, 1988). At Hole 790A, alternating cores showed matching anomalous inclination patterns along the length of the core after $5 \mathrm{mT}$ AF demagnetization. Moreover, when the average inclinations of recovered APC cores was calculated, the values for successive cores alternated between more or less positive values. This is attributed to the alternating use of two APC barrels, which is itself a consequence of operations, whereby one barrel is prepared on the rig floor, while the other is making the round-trip to the seafloor. Schneider and Vandamme suggested (Shipboard Scientific Party, 1988 ) that although the remagnetization may occur in the coring process, "it is more likely that the remagnetization occurs as the core travels up the drill being subjected to repeated shock and vibration."

Features of the various contaminating magnetizations recognized in this early work are near-vertical inclination and variability in magnitude and sign from site to site. The former led to the interpretation that the remanence is an isothermal remanent magnetization (IRM) that is acquired in the axial field within core barrels, although it was

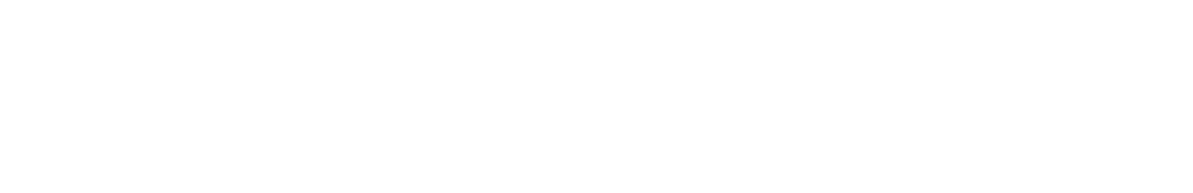


noted that the IRM might be supplemented by some form of grain realignment caused by coring-related vibration and fluidization of the cores (Stokking et al., 1993). The variability of the moment from site to site was thought to reflect variation in lithology and magnetic properties of the sediment (Shibuya et al., 1991).

In addition to the near-vertical magnetization, radial magnetizations of piston cores were reported during Leg 134 (Collot, Greene, Stokking, et al., 1992) and by Schneider and Valet during Leg 154 (Shipboard Scientific Party, 1988). The interpretation of Leg 154 coring-induced magnetization was based on the observed bias in longcore measurements of declination values to $0^{\circ}$, reflecting magnetization in the $+\mathrm{X}$ direction in the ODP coordinate convention. This leg was at low latitude, and the radial magnetization was so strong and hard that aboard ship, long-core measurements were invalidated as a magnetostratigraphic record. Discrete sample measurements were not able to solve the problem, nor were later onshore measurements of u-channels (D.A. Schneider and J.-P. Valet, pers. comm., 1996).

Schneider and Valet (Shipboard Scientific Party, 1988) also showed that in recovered core from Hole 926A, magnetization of discrete samples around the periphery of the core showed strong radial moments, but this magnetization was much reduced in a sample taken from the center of the core. Earlier, a similar observation had been reported in Collot, Greene, and Stokking, et al. (1992). They compared the contamination of samples from the center, middle, and edge of a core, and showed that although the magnetization of the samples from the edge of a core was horizontal, those from the middle and center had significantly downward-directed magnetization.

Recently, Roberts et al. (1996) reported that the lower sections of cores that required overpull ranges of 35,000-50,000 lb for recovery frequently exhibited core "suck-in" within which strong and stable near-vertical magnetizations were observed. This demonstrated that an efficient process of magnetization, such as a stirring remanent magnetization, was involved in these cores where sediment "suck-in" had occurred. To summarize, the following contributions to coringinduced magnetization have been reported:

1. A soft magnetization, involving particle realignment, was usually near vertical and largely demagnetized by fields of $\sim 5 \mathrm{mT}$;

2. A hard magnetization that is near vertical; and

3. A hard magnetization that is radial.

There is not much mystery about (1) because the cores see a predominantly axial field as they move up the drill string in which some IRM must be expected. One way in which (2) can arise is through suck-in (Roberts et al., 1996). There is some confusion concerning (2) and (3), because the coring-induced magnetization is usually referred to as radial, when it would be more correct to refer to a radial horizontal component: the inclination can actually be steep and remain so throughout demagnetization. The magnetic fields of APC core barrels play some role in the coring-induced magnetization, but whether the principal magnetization is acquired during the actual disturbance of the sediments during coring and pullout, or during the journey up the drill string remains to be demonstrated. Both processes involve shock and deformation of the sediment that could bring about particle realignment.

\section{EXPERIMENTAL INVESTIGATIONS OF CORING-INDUCED MAGNETIZATION}

We first describe experiments with a wash core that provided an example of coring-induced magnetization with a radial horizontal component. The demagnetization characteristics of the magnetization were analyzed. The manifestations of drilling-induced magnetizations in well-lithified sediments were also investigated.

\section{The Presence of Radial Coring-Induced Magnetization in a Wash Core from Hole 951B}

To investigate the nature of possible coring-induced magnetization, an experiment was carried out with a wash core that had good recovery. Two 115-cm lengths of a wash core from Hole 951B were cut and measured as a whole core in the $2 \mathrm{G}$ pass-through magnetometer. The magnetization was dominantly in the $\mathrm{z}$ direction (i.e., downcore. The two lengths were then split; one in the standard manner to yield archival and working halves, whereas the other was rotated $90^{\circ}$ from the standard orientation for splitting.

The four halves were then measured in the pass-through magnetometer as if they were archived halves. All four halves gave similar results (Fig. 1), with the dominant $+\mathrm{X}$ component or $0^{\circ}$ declination observed previously in the APC cores from Leg 157. This is consistent with a radial component of magnetization in each of the split halves of wash core because the halves were all placed in the holder of the magnetometer with their curved surfaces down. The radially inward directed magnetization then integrates to give a vertically upward magnetization out of the cut surface. As these were all measured as archived halves, this magnetization is in the $+X$ direction of the ODP coordinate convention.

Progressive demagnetization for the first two half-cores are shown in Figure 2. Figure 2A illustrates the behavior of the first length, which is equivalent to the archived half. The second length, equivalent to the working half, is shown in Figure 2B. If the magnetization had been homogeneous across the cross section of the core,
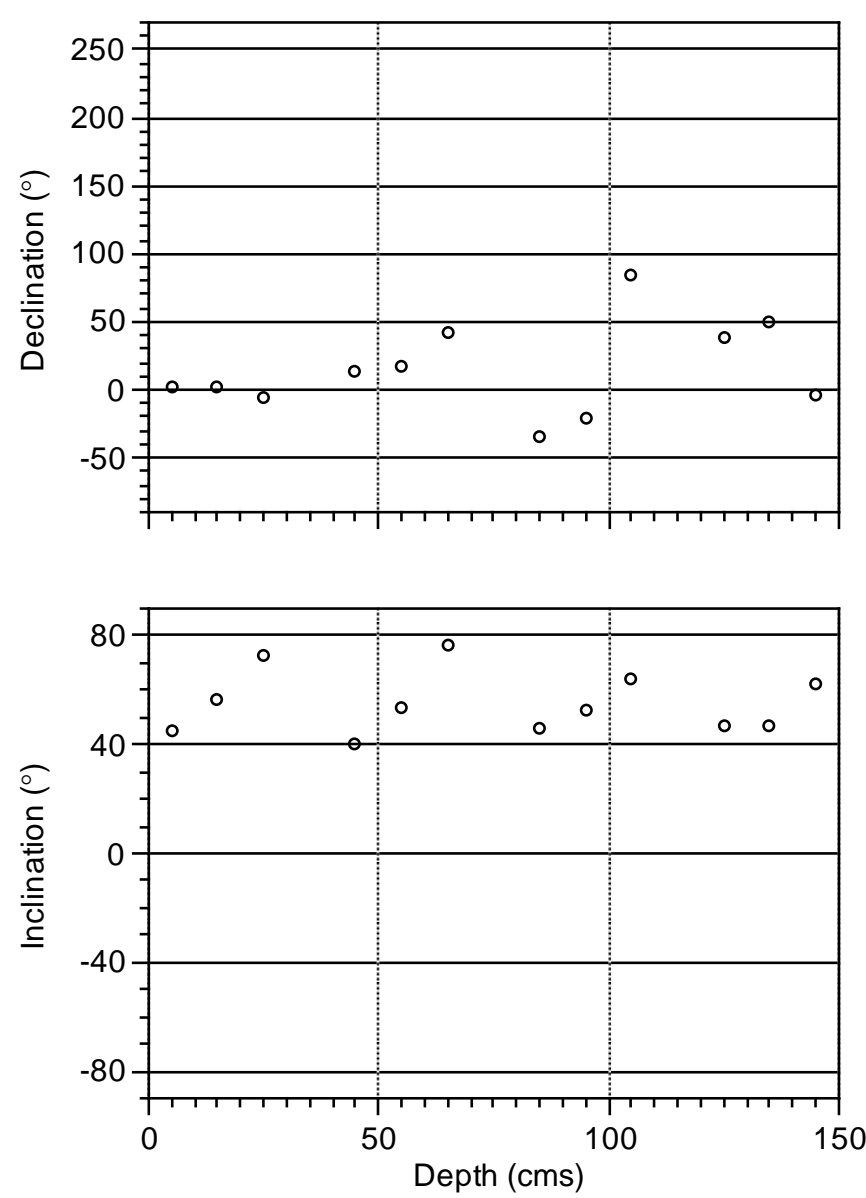

Figure 1. Declination and inclination profiles, after AF demagnetization to $10 \mathrm{mT}$, for four half-cores from the wash core from Hole 951B. There are three readings for each half-core. 


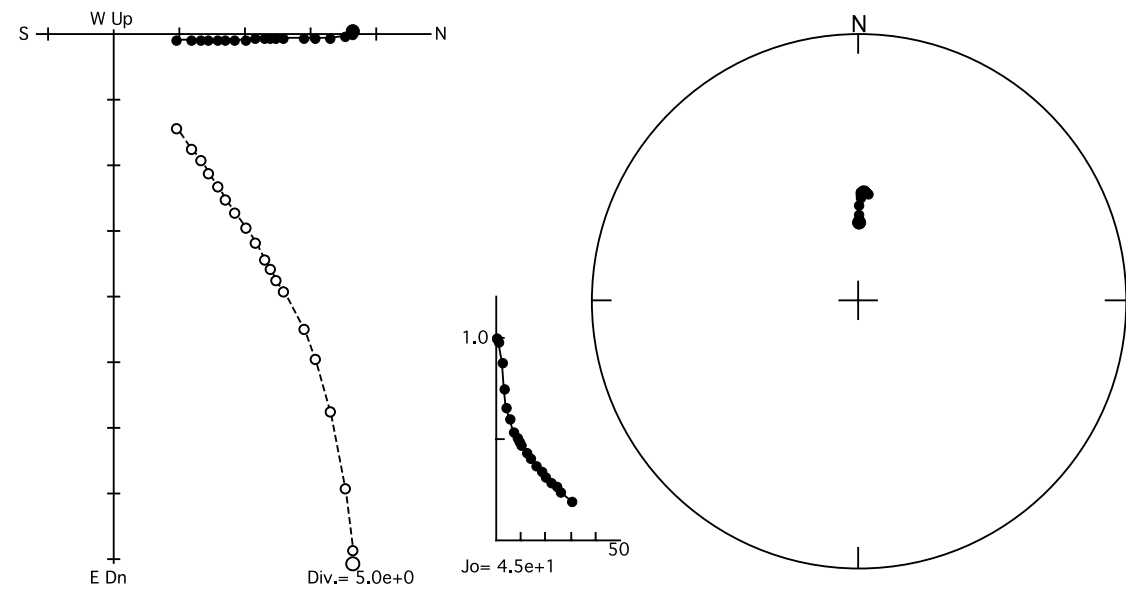

B
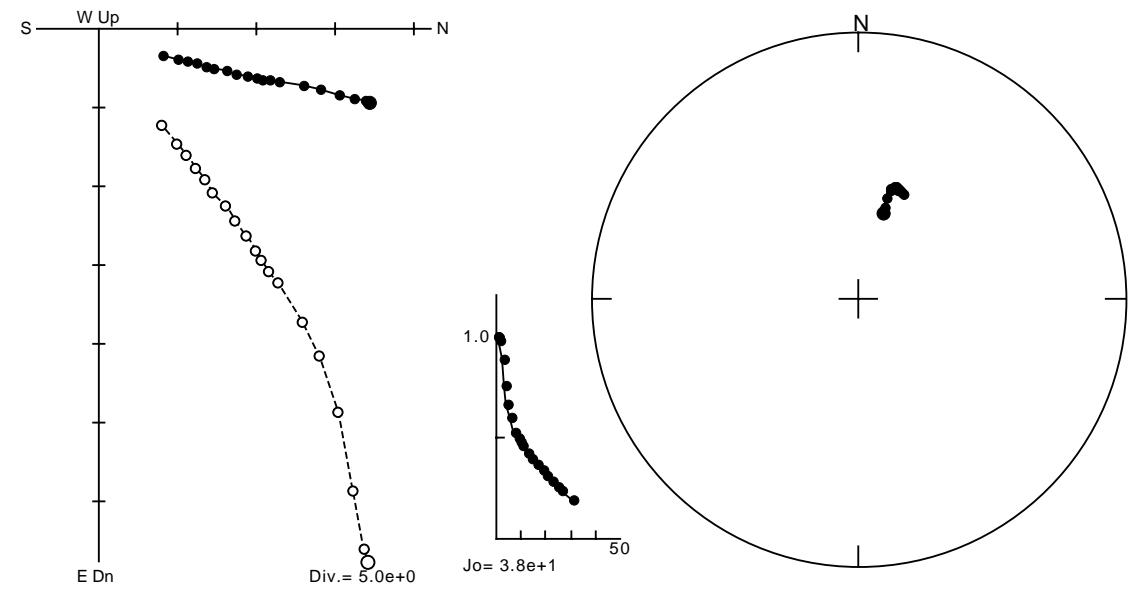

Figure 2. Progressive demagnetization for (A) the archive $(15 \mathrm{~cm})$ and $(\mathbf{B})$ the working $(55 \mathrm{~cm})$ halves of the Hole 951B wash core. Left to right: Zijderveld plot, intensity plot, and equal-area net.

the inversion for measurement would have given a magnetization toward $180^{\circ}$ in the second length. However, the two halves have essentially the same magnetization, which can only be explained by radial magnetization (Fig. 3). Moreover, this is not simply a minor soft overprint; there is little indication of any other magnetization!

The magnitude and demagnetization characteristics of the coringinduced moment of discrete samples from the wash core were compared with those of IRM. In samples from a diagonal profile across the wash core, the horizontal components were systematically inward and the NRM at the margin nearly twice that at the center. After demagnetization the ratio slightly increased. The demagnetization characteristics are illustrated in Figure 4, which demonstrates that this magnetization cannot be an IRM. The same magnitude of IRM has a far smaller coercivity or is softer than the NRM, whereas the appropriate coercivity or hardness of IRM can only be obtained with a much stronger magnetization. Moreover, the ratio of NRM:IRMs is close to $10^{-2}: 1$, which is 1 order of magnitude larger than is typical for the post-depositional remanent magnetization (PDRM) process in the geomagnetic field (Fuller et al., 1988).

Although the observed NRM cannot be explained by simple exposure to a magnetic field in the drill string or after splitting (aboard ship), it is possible that the splitting induces a magnetization that is oriented toward the cut surfaces of the core. However, the observations that the magnetization in the half-cores was almost totally con- tamination, and that in discrete samples the contamination was stronger at the margin of the core, make this unlikely possibility even less plausible.

This wash core experiment strongly suggests that the magnetization was acquired during the coring process or recovery before the core was brought aboard ship. The magnetization appears to involve particle realignment in coring-induced sediment deformation which generates a relatively hard magnetization. Whether this takes place during coring, pullout, or passage up the drill pipe, is not clear.

\section{Magnetization of Well-Lithified Sediments from an RCB Core}

If coring-induced magnetization involves the realignment of magnetic particles, then well-lithified sediments within which particle realignment is impossible should not exhibit the effect. We therefore investigated the magnetization of well-lithified samples from RCB cores.

As an example of the behavior of the samples from the RCB cores, Figure 5 shows the alternating magnetic fields (AF) demagnetization of Sample 157-954B-21R-4, 24-26 cm. It carries a soft, nearvertical downward magnetization, most of which is removed by $\sim 5$ $\mathrm{mT}$ demagnetization. The remainder of the magnetization exhibits an inclination of between $43^{\circ}$ and $50^{\circ}$, which is appropriate for the $29^{\circ} \mathrm{N}$ 
CASE 1: Whole core homogeneously magnetized

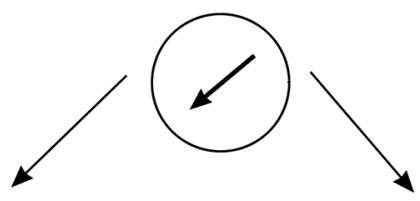

Working Half

Two Halves Differ

Archive Half
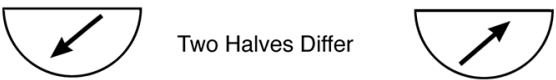

CASE 2: Whole core radially magnetized

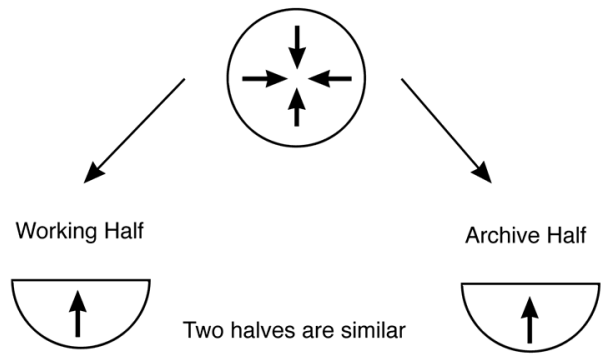

Figure 3. Demonstration of radial magnetization in wash core from Hole 951B, showing (top) homogeneous magnetization and (bottom) a horizontal component directed radially inward.

latitude of the site. Moreover, the ratio of the NRM:IRMs is $10^{-3}: 1$, which is appropriate for the PDRM process (Fuller et al., 1988). It therefore appears that this sample, like other well-lithified samples studied, does not show the high-coercivity coring- or drilling-induced magnetization as seen in the APC cores.

\section{Summary}

The studies of the Hole 951B wash core and the RCB cores show that the coring-induced magnetization can dominate the magnetization of an APC core, whereas it is not seen in RCB core samples studied. This suggests that the coring-induced contamination does indeed require the realignment of magnetic particles, which can take place in the poorly lithified sediments cored with the APC system. In welllithified sediments, the magnetic particles are sufficiently well locked into position so that realignment is not possible and that no highcoercivity, drilling-induced magnetization takes place. A wash core is not a standard core, but the almost $100 \%$ recovery of this core makes this one a good analogue for standard cores, and its magnetic behavior is of interest.

\section{MEASURING MAGNETIC FIELDS ASSOCIATED WITH BHA AND APC BARRELS, CUTTING SHOES, AND DRILL BITS}

During Leg 157, preliminary observations were made of the magnetic fields associated with extended core barrel (XCB) drill bits and collars and on an APC collar and cutting shoe. The XCB drill bit was mounted on a used collar, and the radial field within the bit was measured. Profiles across the inside of the drill bit revealed that the field fell toward the center and consistently radiated outward. Radially outward fields of as much as $13 \mathrm{mT}$ were measured with the maximum fields at the teeth of the bit (Table 1). The tangential field was 1 order of magnitude weaker. The collar and bit were then separated and their fields measured. The fields within the drill bit were 1 order of magnitude smaller when it was measured separately (Table 2). After inverting the bit and collar and remeasuring their fields, it became clear that the magnetization of the drill bit was an induced magnetization, but that the collar carried significant remanent magnetization. The fields in a second core bit, which was new, were radially inward and weaker than in the first bit. These preliminary results suggested the need for more systematic and extensive measurements that were eventually carried out during Leg 166T.

\section{Measuring Magnetic Fields Associated with BHAs}

During the port call at Panama City, BHAs used previously in APC coring were suspended from the heave compensator to simulate the situation during coring, and the fields in the vicinity of the drill bit were measured. A monel collar was substituted for the top collar, where it would normally be placed for the tensor tool, and the assembly remeasured. The drill bit (\#478455) had been used for a total of $79.6 \mathrm{hr}$ during Leg 166.

The measurements were made with a Walker Scientific, MG-5D Gaussmeter with axial and transverse probes. The quoted accuracy for the range that we used was 5 microT, but movement of the assembly, with respect to the measuring jig, gave repeat readings that were only good to $\sim 20 \%$. Measurements of the vertical, radial, and transverse B-fields were made along $45^{\circ}$ radials at distances of $0,5,10$, $15,20,30,40$, and $50 \mathrm{~cm}$ from the center of the drill bit. The measurements were made immediately below the drill bit and at 10 and $30 \mathrm{~cm}$ below this. The roller cones of the drill bit were centered at $0^{\circ}$, $90^{\circ}, 180^{\circ}$, and $270^{\circ}$. The $0^{\circ}$ fiducial line of the jig was aligned with magnetic north, which happened to be approximately abeam on the port side of the ship.

Results for the BHA to which the monel collar was attached are shown in Figure 6. The strongest field is axial with the maximum value approaching $4 \mathrm{mT}$ (Fig. 6A) immediately beneath one of the roller cones of the drill bit (i.e., $15 \mathrm{~cm}$ along the $0^{\circ}$ radial). This field is everywhere downward. The fields have fallen substantially by $10 \mathrm{~cm}$ below the drill bit (Fig. 6B) and fall by 1 order of magnitude at $30 \mathrm{~cm}$ below. The next largest field is the radial, which is close to $1 \mathrm{mT}$ apart from immediately alongside the roller cones (Fig. 6C). The field is predominantly outward outside of the BHA (i.e., beyond $15 \mathrm{~cm}$ on the radials), but inside it is inward. The transverse field is the weakest with values of little more than $0.5 \mathrm{mT}$, even immediately under the bit. The fields observed for the two assemblies were not significantly different to the accuracy of our observations, so that the presence of the monel collar has little effect at the level of the drill bit.

\section{Measuring Fields of APC Barrels with Cutting Shoes}

Three APC core barrels were suspended from the heave compensator to simulate APC drilling with the piston core barrel extended. Measurements were made of the vertical, radial, and tangential fields in the core barrel. In addition, a survey was carried out below the cutting shoe of the first APC. The axial field was measured at the center of the barrel and at $90^{\circ}$ intervals $\sim 5 \mathrm{~mm}$ from the inner wall of the barrel. The tangential and radial fields were measured around the periphery, $5 \mathrm{~mm}$ from the inner wall at the same $90^{\circ}$ intervals.

Vertically upward fields of as much as $10 \mathrm{mT}$ were found $5 \mathrm{~mm}$ from the inner wall of the barrel, whereas the axial fields at the center of the barrel were of the order of $\mathrm{mT}$ (Fig. 7A). The radial fields were inward and predominantly in the range of $\mathrm{mT}$ (Fig. 7B). Tangential 

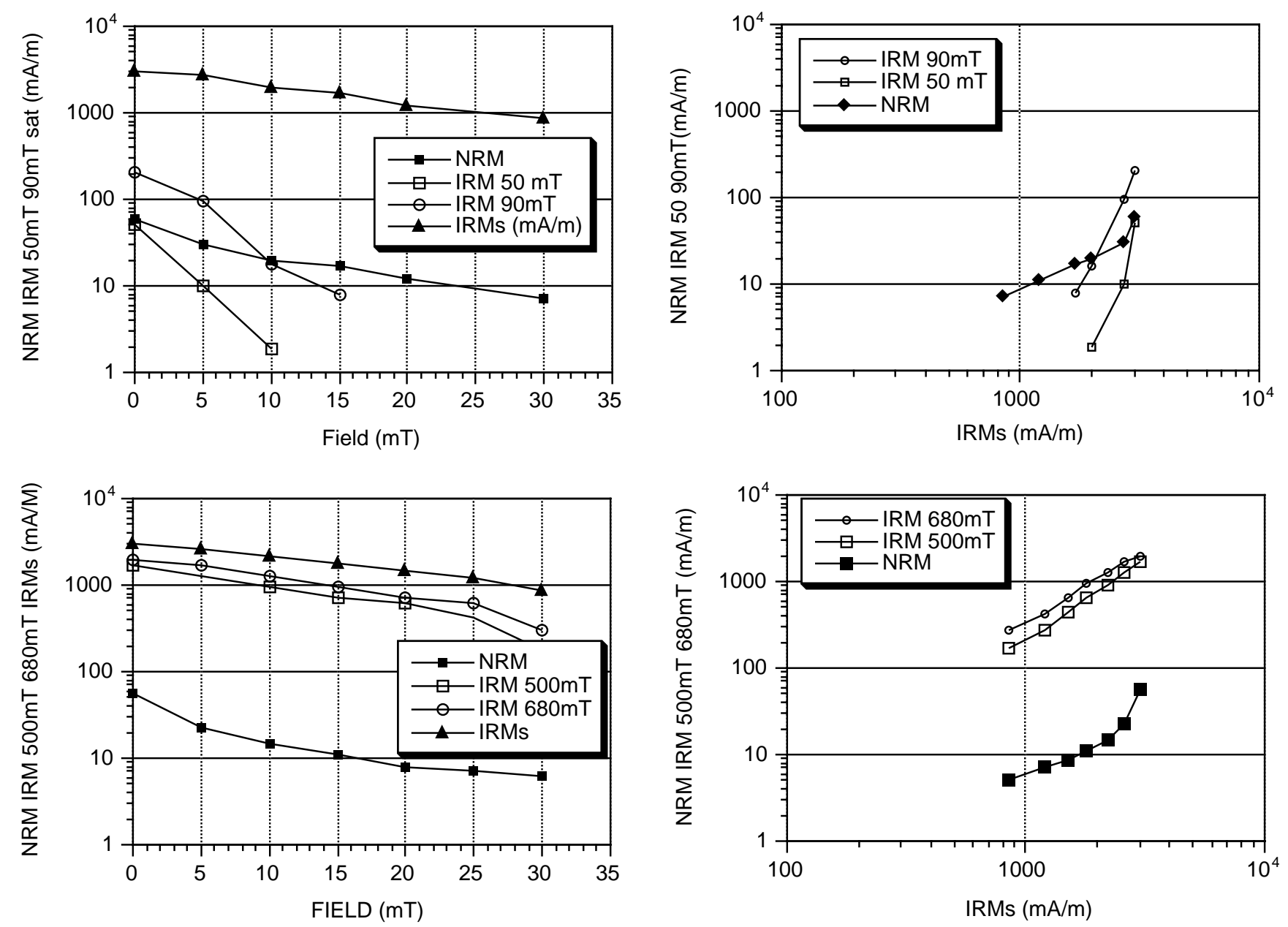

Figure 4. Comparison of AF demagnetization characteristics of NRM and IRM of a wash core from Hole 951B. Top. IRM of comparable intensity. Bottom. The IRM of comparable hardness.

fields were comparable with the vertical fields and larger than the radial fields (Fig. 7C).

The third APC had the piston in the core barrel. This had a large downward and radially outward directed field. We determined that this field was because of the piston by measuring the outside of the barrel, where we saw only the typical lower field of the barrel. Below the cutting shoe, the vertical field was downward and fell systematically with depth below the cutting shoe and with distance outward along the radials.

\section{Magnetic Fields of Cutting Shoes}

Measurements similar to those made with the APC cores were also made for standard shoes and the Adara temperature tool shoes. We were able to investigate new and used standard shoes, as well as several Adara tool shoes, all of which had been used.

The Adara tool shoes had similar patterns with upward axial fields reaching a few tenths of a $\mathrm{mT}$ (Fig. 8A, B). The radial fields were much weaker except at the bottom of the cutter, where they also reached the level of $0.1 \mathrm{mT}$.

The new standard cutting shoe had a downward axial field and an outward radial field (Fig. 8C). The fields in the used cutting shoes were stronger than and opposite in sign to those in the new shoes (Fig. 8D). Immediately below the cutting surface of the old shoe a field of $1 \mathrm{mT}$ was found. By inverting the cutting shoes and remeasuring the fields, we demonstrated that the fields were all caused by the remanent magnetizations of the shoes.

\section{Discussion}

The strong magnetization of the core barrels provide a potential source field in which the sediments could acquire coring-induced magnetization. These fields can account for the soft IRM-like nearvertical magnetization. The magnetic fields in the majority of the core barrels and shoes were radially inward, which is the more common direction of coring-induced moments in the recovered cores. The cutting surface of the used shoes were frequently found with iron filings attracted to them! The core barrels and shoes are thus good candidates for the sources of the fields in which the coring-induced moments are acquired, but the magnitudes of the radial fields are smaller than the tangential fields. Evidently, the principal fields to which the sediments are exposed during coring are the same relatively strong fields of the APC barrels and cutting shoes.

\section{SIMULATION OF THE RADIAL CORING-INDUCED MOMENT AND CRITERIA FOR ITS RECOGNITION}

In principle, the effect of the radial horizontal component of the coring-induced moments can be modeled providing that one knows 
A

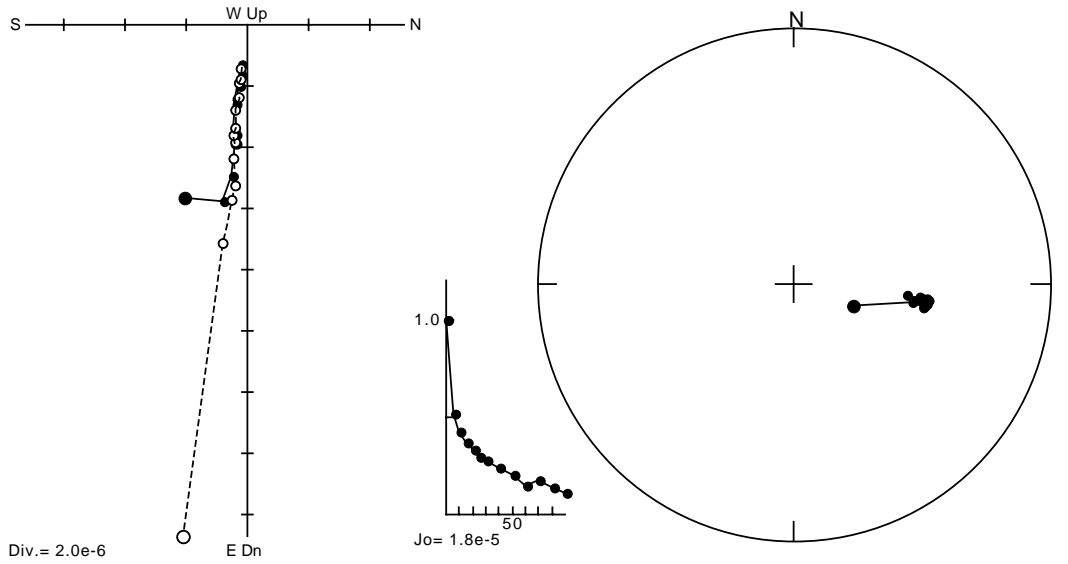

B

Figure 5. AF demagnetization behavior of Sample 157-954B-21R-4, 24-26 cm. A. Left to right: Zijderveld diagram, intensity plot, and an equal-area plot. B. AF demagnetization characteristics.

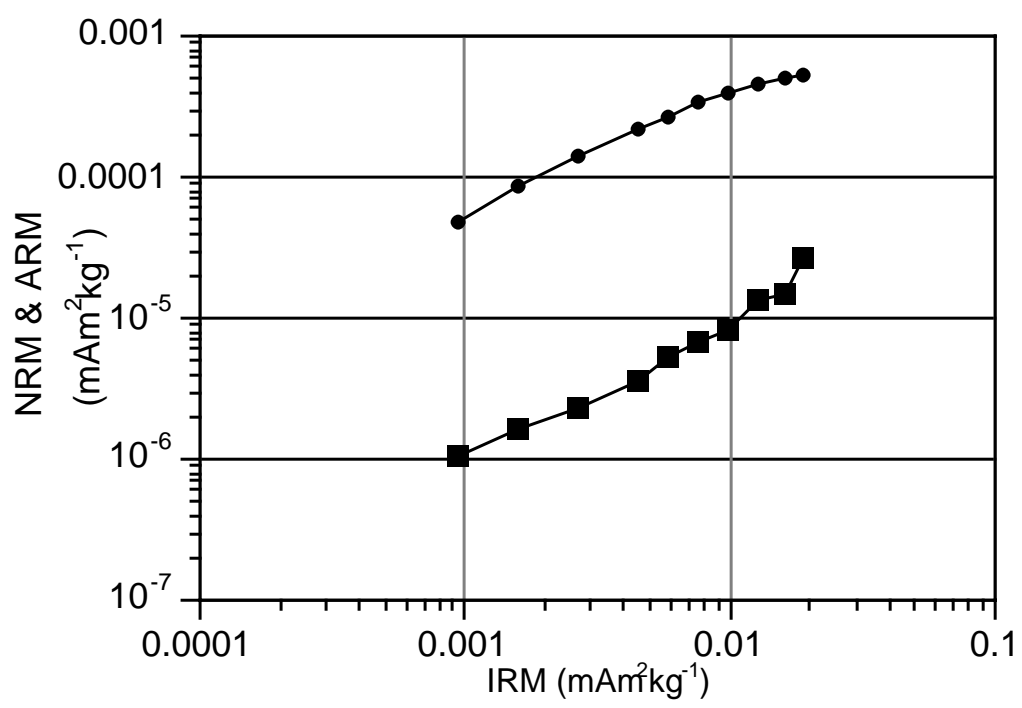

Table 1. Magnetic field of XCB drill bit and collar with radial field profiles across interior of drill bit.

\begin{tabular}{lcc}
\hline Position on profile: & $\begin{array}{c}\text { Field Profile 1 } \\
(\mathrm{mT})\end{array}$ & $\begin{array}{c}\text { Field Profile 2 } \\
(\mathrm{mT})\end{array}$ \\
\hline Margin & 13.0 & 4.5 \\
0.5 radius & 2.5 & 2.1 \\
Center & -2.0 & -2.5 \\
0.5 radius & -4.5 & -4.5 \\
Margin & -7.0 & -8.0 \\
\hline
\end{tabular}

whether the magnetization is radially outward or inward. By far, the most common situation is that the radial moment is inward, giving a preponderance of $0^{\circ}$ declinations in archived half-core measurements before correction to geographic coordinates. The drill moment in the working half is actually in the $-\mathrm{X}$ direction in the ODP convention (i.e., $180^{\circ}$ from the fiducial line). We assume this in the following discussion. The angle between the fiducial line and the geomagnetic field at the site is given by the tensor tool measurement. The direction of the horizontal component of the coring-induced moment is therefore known in geographical coordinates, providing that orientation is

Table 2. Magnetic field within drill bit with radial fields adjacent to interior surface of drill bit.

\begin{tabular}{ccc}
\hline Position & $\begin{array}{c}\text { Field (drill collar attached) } \\
(\mathrm{mT})\end{array}$ & $\begin{array}{c}\text { Field (drill alone) } \\
(\mathrm{mT})\end{array}$ \\
\hline 1 & 0.4 & 0.09 \\
1.1 & 0.1 & 0.07 \\
1.2 & 1.5 & 0.70 \\
2 & 0.2 & -0.11 \\
2.1 & 0.6 & 0.22 \\
2.2 & 1.2 & 0.28 \\
3 & 0.8 & 0.11 \\
3.1 & 1.2 & 0.20 \\
3.2 & 2.4 & 0.46 \\
4 & 0.4 & 0.20 \\
4.1 & 0.6 & 0.10 \\
4.2 & 2.0 & 0.30 \\
5 & 0.3 & 0.08 \\
5.1 & 1.3 & 0.33 \\
5.2 & 2.3 & 0.34 \\
\end{tabular}

Notes: Positions 1, 2, etc., are between teeth of drill bit. Positions 1.1, 2.1 etc., are alongside the support of the tooth, and positions $1.3,2.3$, etc., are alongside the teeth. 
A

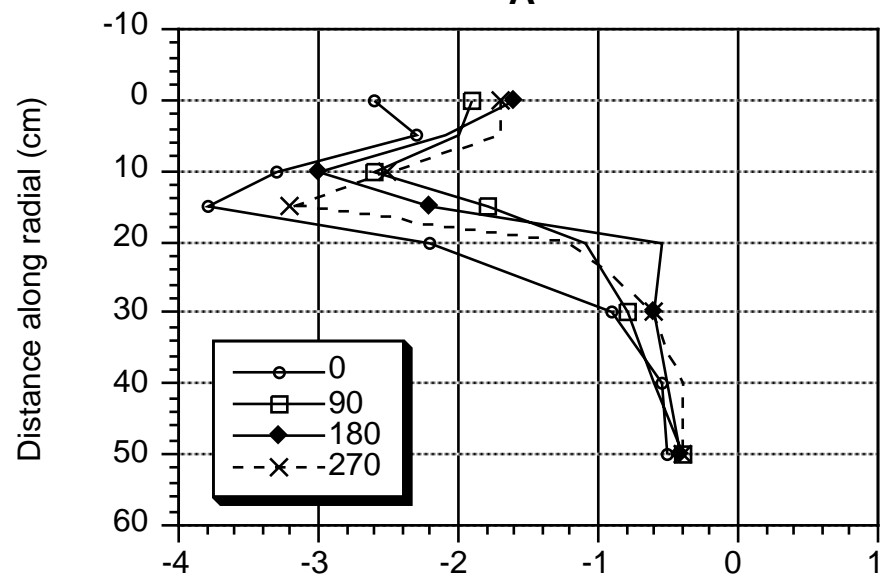

C

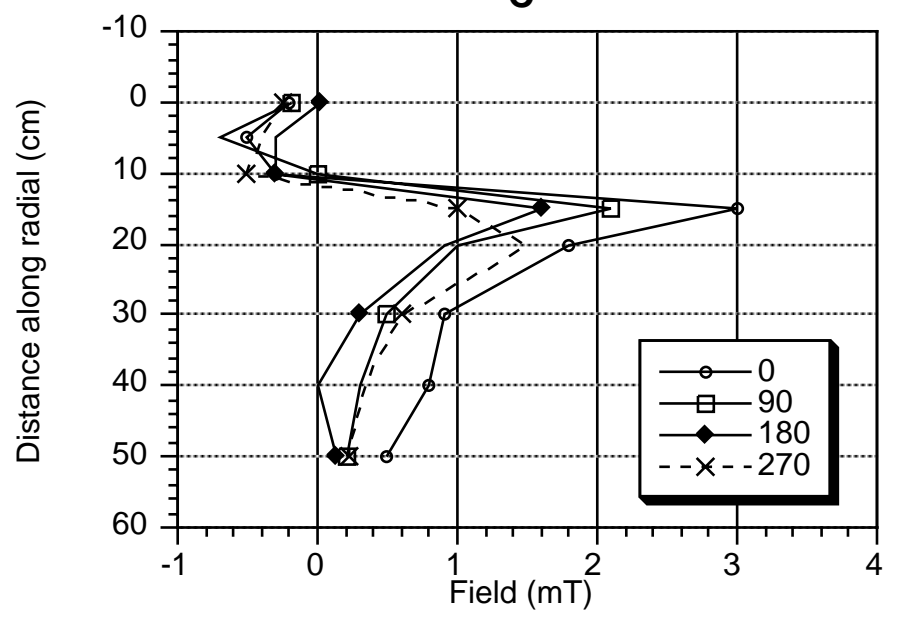

B

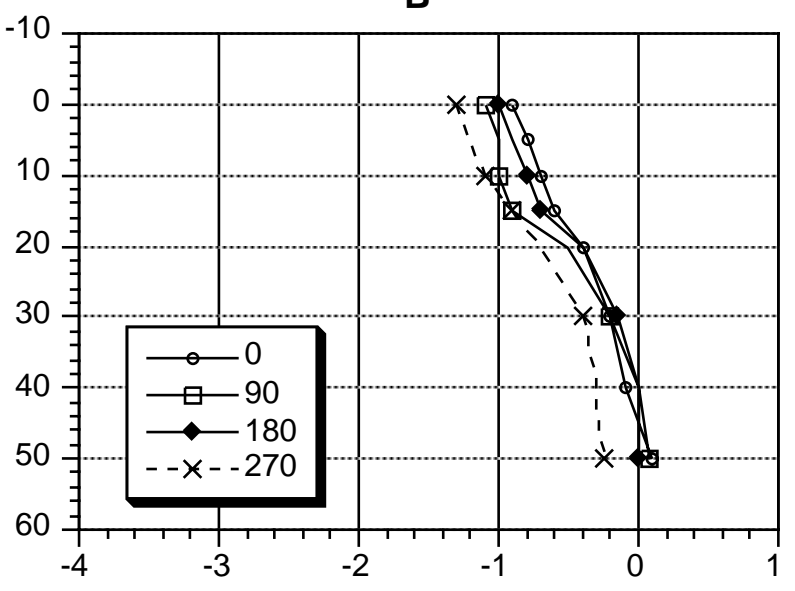

Figure 6. Fields measured below the bore-hole assembly. A. Vertical field immediately below drill bit (+/ve up). B. Vertical field $10 \mathrm{~cm}$ below drill bit (+/ve up). C. Radial field immediately below drill bit (+/ve out). D. Tangential field immediately below drill bit (+/ve CW).

successful. We can then model the horizontal component of the coring-induced moment.

\section{Simulating the Effect of Drill Moments}

To illustrate the effect of the horizontal coring-induced drill moment, a $10 \%$ radial coring-induced moment was added to a synthetic record of a field reversal. As examples, coring-induced moments were added in the $+\mathrm{X}$ direction and in the $+\mathrm{Y}$ direction. The two arbitrarily chosen directions for the drill moment correspond to inwarddirected radial moments in samples taken from the center of the working half, with tensor tool orientations of $180^{\circ}$ and $270^{\circ}$. The results are shown as declination, inclination, and intensity plots in Figure 9 and as plots of virtual geomagnetic poles (VGPs) in Figure 10. In each figure the magnetization, including the drill moment, is compared with the initial magnetization.

The initial magnetization reflects a geomagnetic field reversal from normal to reversed with a near-sided path (i.e., the VGP passes beneath the site). Changes in declination and intensity are symmetri$\mathrm{cal}$, and the directions and VGPs before and after the reversal are antipodal. The addition of $10 \%$ in the $+\mathrm{X}$ direction makes only small changes in declination, inclination, and intensity. Nor do the VGPs show a strong effect of the drill moment. The addition of $10 \%$ drill moment in the $\mathrm{Y}$ direction has little effect on inclination and intensi- ty, but has pronounced effects on declination and the VGPs. The drill moment moves the VGPs to the east of the site.

Numerical simulations of the effect of a stable component of drilling contamination reveal that it can distort the normal and reversed directions to make them non-antipodal. In studies of reversal records, the contamination can distort the VGP path producing large effects when the NRM intensity is low. If the fiducial line on the core is oriented close to north or south, the drill moment produces a nonantipodal distribution of VGPs in the two hemispheres. If it is oriented closer to east or west, the moment deflects the path with the maximum effect at the lowest latitude VGPs.

This analysis does not include the vertical component of the coring-induced magnetization; however, its effects can be anticipated. For example, if a hard vertical upward component occurs in cores approximate to the northern latitudes, it will increase the scatter of normal poles compared with the reversed. Conversely, if it is in the downward direction, it will behave more like a normal overprint by producing an increased scatter in reversed poles.

\section{Discussion}

The results of the wash core experiment are consistent with the overwhelming preponderance of inward radial horizontal components of coring-induced magnetization. The relatively strong ob- 
A

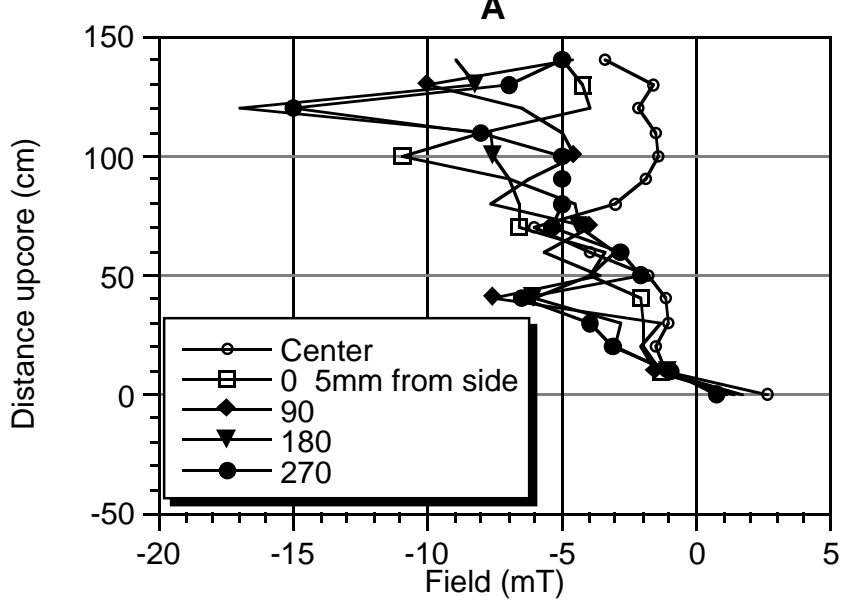

B

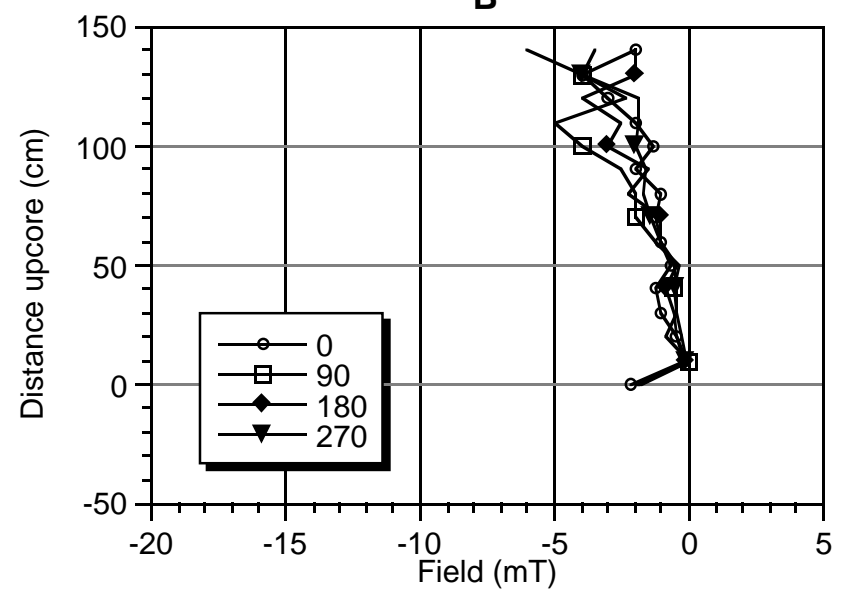

C

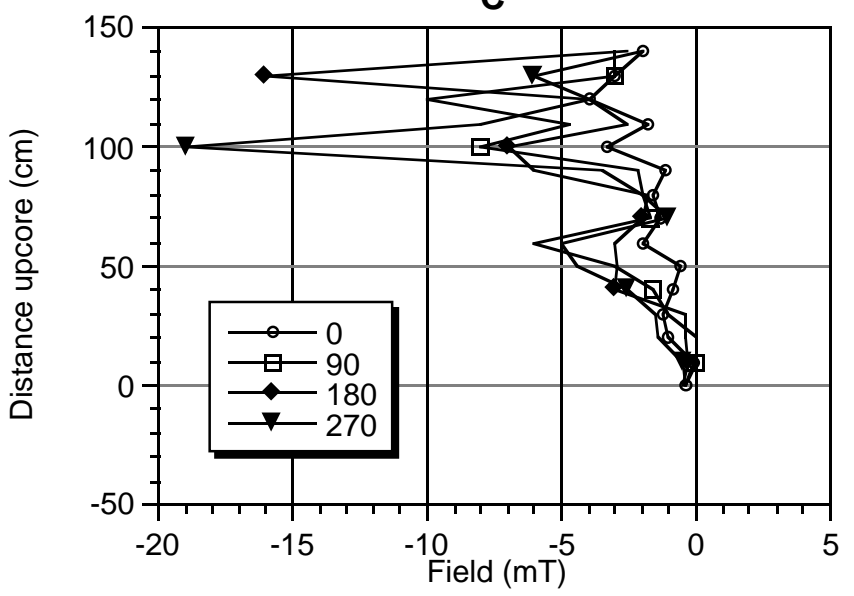

Figure 7. Fields within APC inner core barrels. A. Axial field (+/ve down). B. Radial field (+/ve out). C. Tangential field (+/ve CW). Distance upcore is the distance above the bottom of the cutting shoe.

served fields of the BHA, APC barrels, and cutting shoes suggest that they may play a role in magnetization. However, the BHA fields seem unlikely to be important source fields because they are weaker than the APC barrel fields and the fields of the cutting shoes. Moreover, the recovered sediment is in direct contact with the APC barrels and cutting shoes, but not with the BHA. The strong fields in the APC barrels considered in conjunction with the demonstration by Schneider and Vandamme (Shipboard Scientific Party, 1988) that the anomalies in the recovered sediments could be correlated with the use of a particular APC barrel suggests that the APC fields are a likely source field for coring-induced magnetization. If the magnetization is indeed acquired in the field of the APC barrel, it can happen either as the sediment initially enters the APC during pullout or during passage up the drill string. The first possibility may involve a thixotropic setting of the sediment as it comes to rest with respect to the APC barrel. The pullout can give rise to magnetization as Roberts et al. (1996) reported, but whether this occurs when there is not obvious suck-in is not clear. If the magnetization is acquired during passage up the drill string, it would be some form of shock magnetization process as the APC core repeatedly strikes the drill string and the sediment is shaken, thereby permitting some particle realignment.

\section{CONCLUSION}

Further experimental investigation is needed to establish the details of the mechanism of the radial drill moments. To investigate the role of the passage up the drill string, demagnetized core lengths could be sent down the drill string and returned to the ship and remeasured. To investigate the effect of the coring process, core could be recovered with standard piston coring devices thereby avoiding passage up a drill string. Coring could then be carried out under a number of conditions to investigate the effect of magnetic vs. nonmagnetic cutting shoes and barrels.

The existence of a coring-induced magnetic contamination effect is no longer in doubt. At certain low-latitude sites, where the vertical component is small, results have been so poor that they interfere with the magnetostratigraphy from shipboard measurements. In general, the effects are less severe, and on some legs, no significant drill moments are reported. The nature of the variability of this coringinduced magnetization is an unresolved puzzle. However, the fact that it is so variable suggests that it cannot simply be the coring process. It is more likely to be some combination of coring and recovery, especially of poorly lithified sediments in the presence of the magnetic fields of the APC barrels and cutting shoes.

\section{ACKNOWLEDGMENTS}

It is a pleasure to acknowledge the help that we received from many people aboard ship. We would especially like to thank from Leg 157, Ron Grout and Bob Caldow, and from Leg 166T, Bob Caldow, Gene Pollard, Mark Robinson, Robert Owens and the crew, Tim McGowan, Cesar Flores, and Anne Pimmel. Mike Fuller wishes 
A

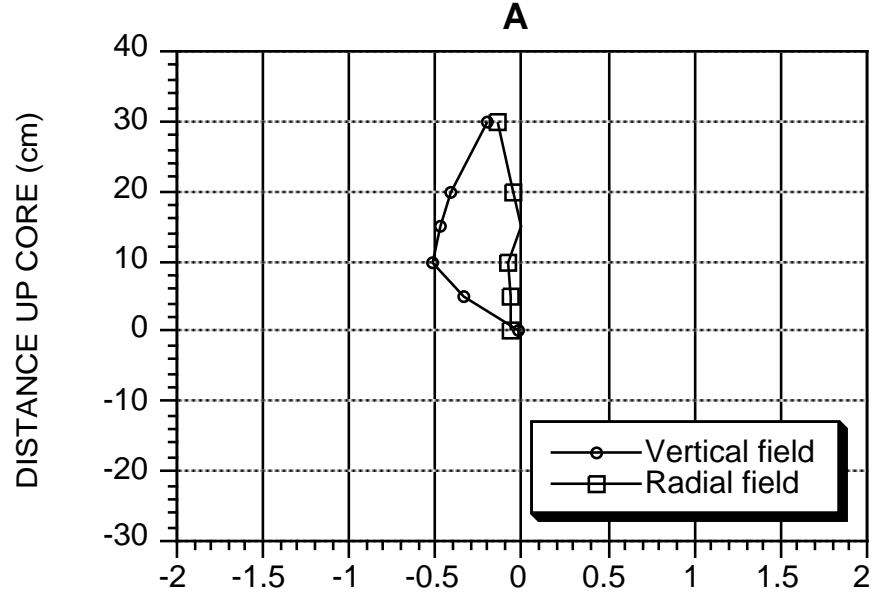

C

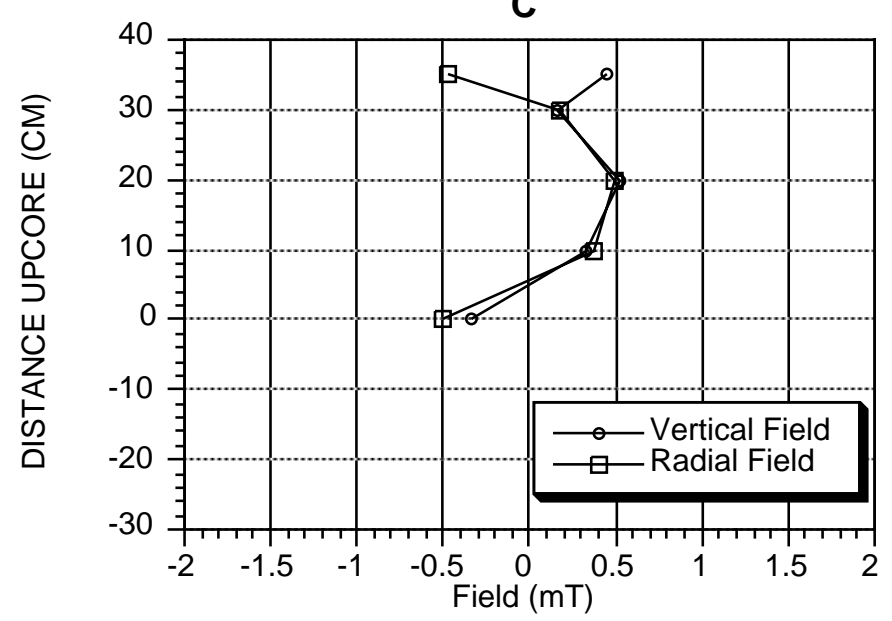

B

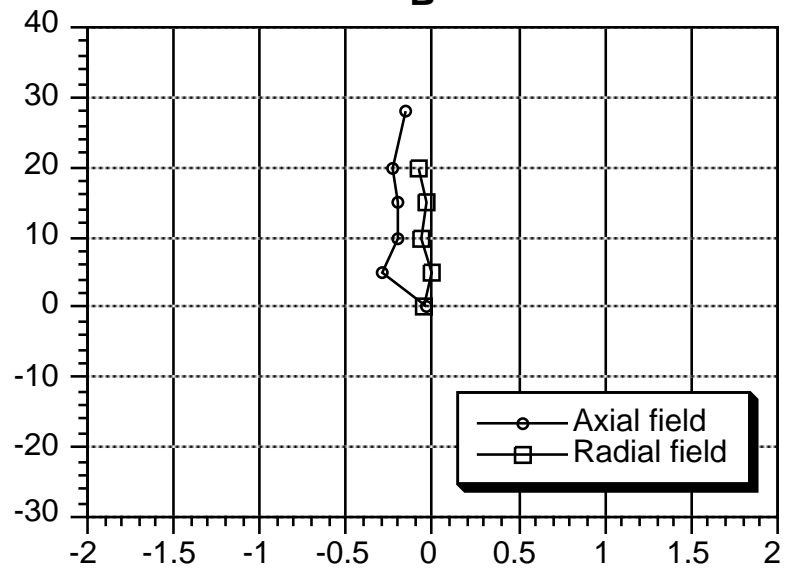

D

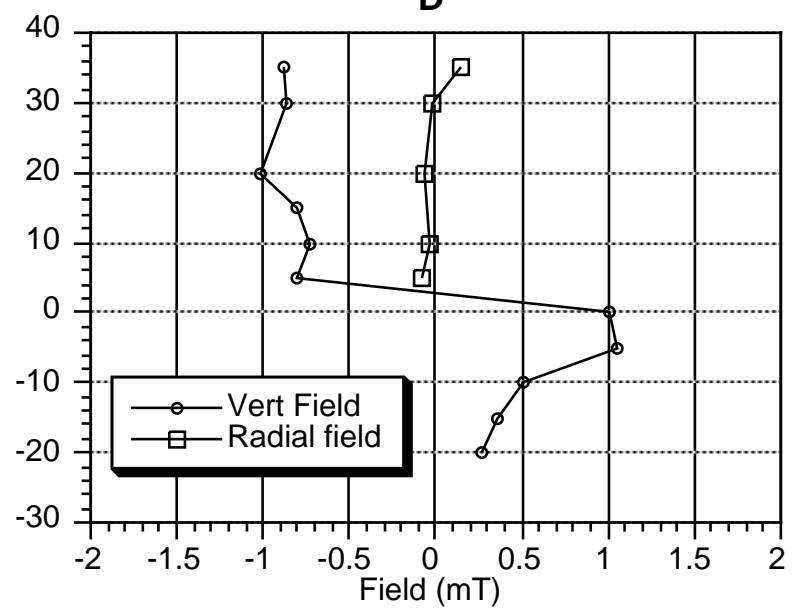

Figure 8. Fields in cutting shoes: Axial (+/ve down) and radial (+/ve out) fields in cutting shoes. A. Used Adara tool shoe \#1. B. Used Adara tool shoe \#2. C. Used new standard shoe. D. Used standard shoe. Distance upcore is the distance above the bottom of the cutting shoe.

to thank Karen Fuller for help with the graphics. This is publication 964 of HIGP and 4544 of SOEST.

\section{REFERENCES}

Barton, C.E., and Bloemendal, J., 1986. Paleomagnetism of sediments collected during Leg 90, Southwest Pacific. In Kennett, J.P., von der Borch, C.C., et al., Init. Repts. DSDP, 90: Washington (U.S. Govt. Printing Office), 1273-1316.

Bleil, U., 1989. Magnetostratigraphy of Neogene and Quaternary sediment series from the Norwegian Sea: Ocean Drilling Program, Leg 104. In Eldholm, O., Thiede, J., Taylor, E., et al., Proc. ODP, Sci. Results, 104: College Station, TX (Ocean Drilling Program), 829-901.

Fuller, M., Cisowski, S., Hart, M., Haston, R., Schmidtke, E., and Jarrard, R., 1988. NRM:IRM demagnetization plots: an aid to the interpretation of natural remanent magnetization. Geophys. Res. Lett., 15:518-521.

Hall, S.A., and Sager, W.W., 1990. Paleomagnetic and rock magnetic properties of sediment samples from Ocean Drilling Program Leg 116, central Indian Ocean. In Cochran, J.R., Stow, D.A.V., et al., Proc. ODP, Sci. Results, 116: College Station, TX (Ocean Drilling Program), 337-344.

Roberts, A.P., Stoner, J.S., and Richter, C., 1996. Coring-induced magnetic overprints and limitations of the long-core paleomagnetic measurements technique: some observations from Leg 160, Eastern Mediterranean Sea. In Emeis, K.-C., Robertson, A.H.F., Richter, C., et al., Proc. ODP, Init. Repts., 160: College Station, TX (Ocean Drilling Program), 497-505.
Shipboard Scientific Party, 1995. Site 926. In Curry, W.B., Shackleton, N.J., Richter, C., et al., Proc. ODP, Init. Repts., 154: College Station, TX (Ocean Drilling Program), 153-232.

Shipboard Scientific Party, 1988. Site 709. In Backman, J., Duncan, R.A., et al., Proc. ODP, Init. Repts., 115: College Station, TX (Ocean Drilling Program), 459-588.

Shibuya, H., Merrill, D.L., Hsu, V., and Leg 124 Shipboard Scientific Party, 1991. Paleogene counterclockwise rotation of the Celebes Sea-orientation of ODP cores utilizing the secondary magnetization. In Silver, E.A., Rangin, C., von Breymann, M.T., et al., Proc. ODP, Sci. Results, 124: College Station, TX (Ocean Drilling Program), 519-523.

Stokking, L.B., Musgrave R.J., Bontempo, D., and Autio, W., 1993. Handbook for Shipboard Paleomagnetists. ODP Tech. Note, 18: College Station, TX (Ocean Drilling Program).

Tauxe, L., Valet, J.-P., and Bloemendal, J., 1989. Magnetostratigraphy of Leg 108 advanced hydraulic piston cores. In Ruddiman, W., Sarnthein, M., et al., Proc. ODP, Sci. Results, 108: College Station, TX (Ocean Drilling Program), 429-439.

Date of initial receipt: 10 June 1996

Date of acceptance: 8 March 1997 Ms 157SR-103 

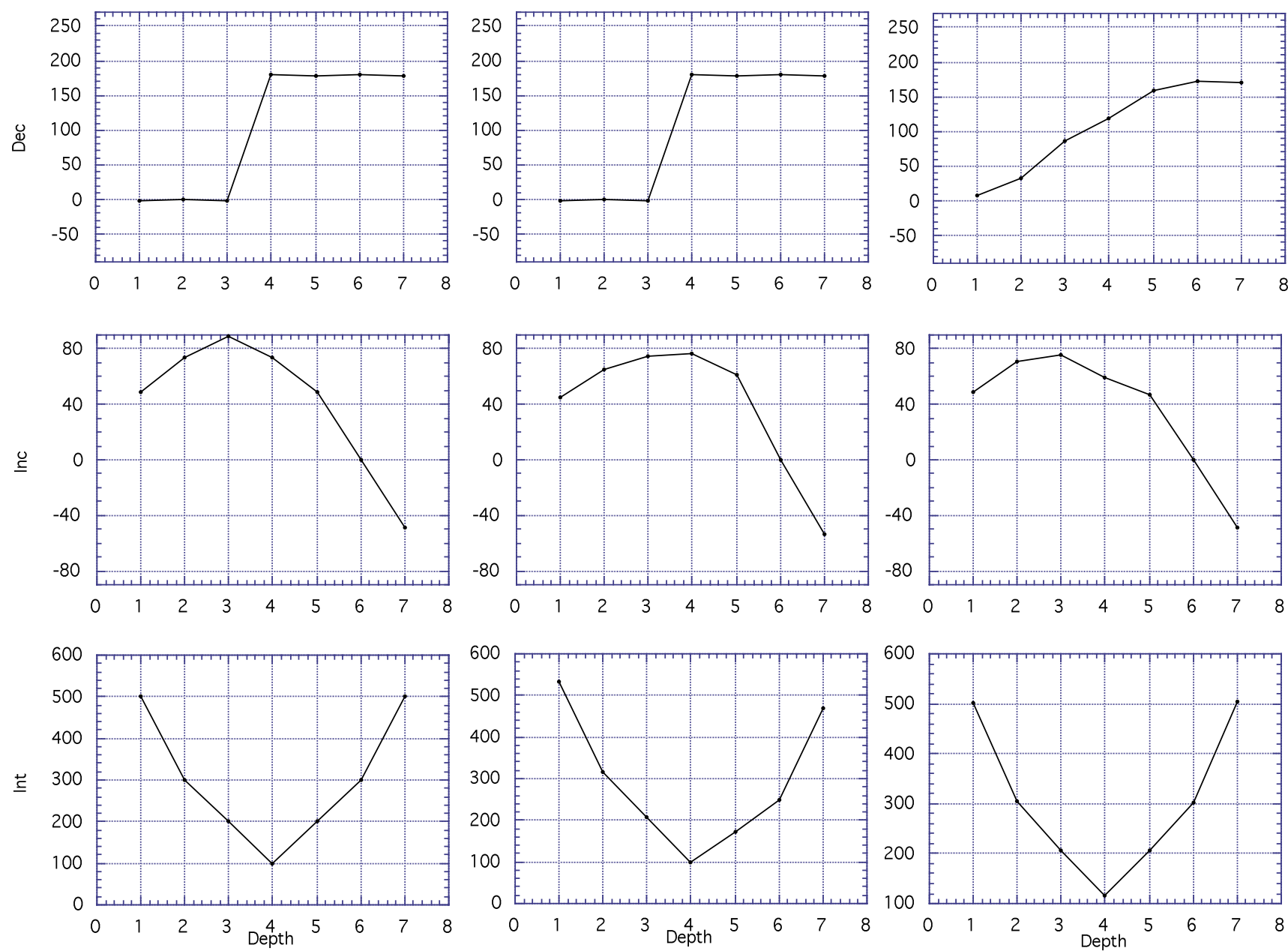

Figure 9. Declination, inclination, and intensity plots for simulation of effect of coring-induced moments.
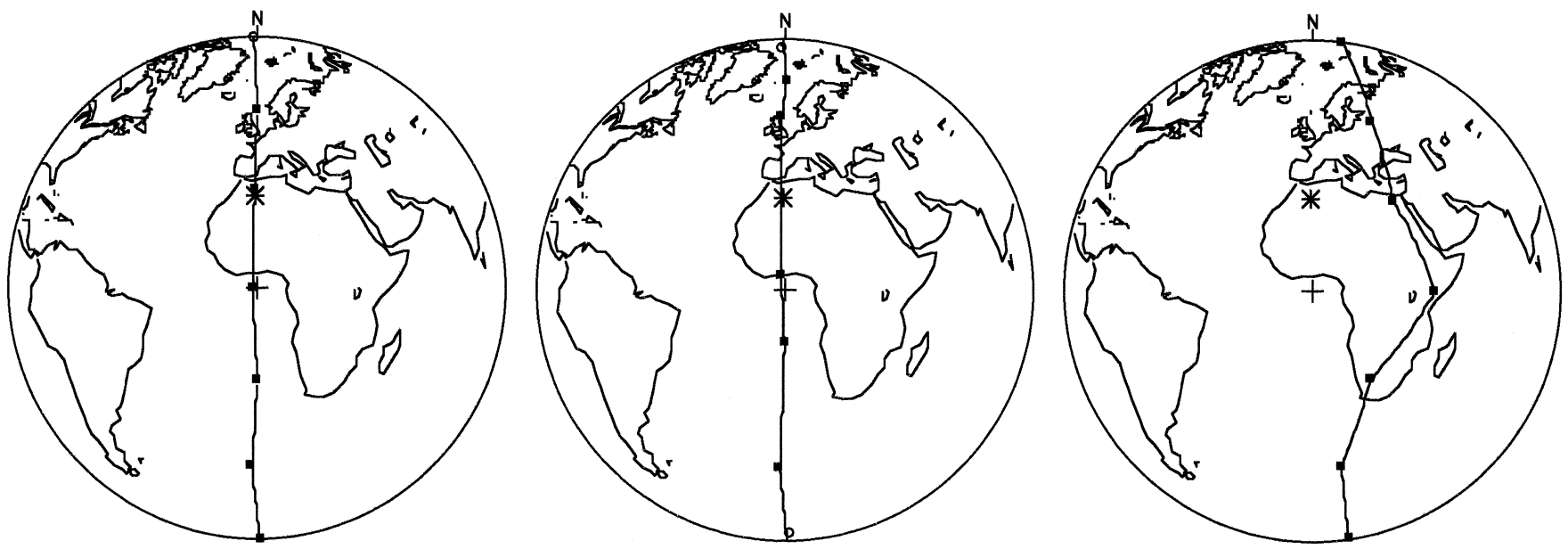

Figure 10. VGPs for simulation of the effect of coring-induced moments. 